\title{
DR4 prevalence related to the age at disease onset ir female patients with rheumatoid arthritis
}

\author{
J M W HAZES, ${ }^{1}$ B A C DIJKMANS, ${ }^{1}$ J M HOEVERS, ${ }^{1}$ J J M JANSON, \\ R R P DE VRIES, ${ }^{2}$ J P VANDENBROUCKE ${ }^{3}$ AND A CATS \\ From the Departments of ${ }^{1}$ Rheumatology, ${ }^{2}$ Immunohaematology and Bloodbank, and ${ }^{3}$ Clinical \\ Epidemiology, University Hospital Leiden, The Netherlands
}

SUMMARY The prevalence of HLA-DR4 in relation to age at disease onset was calculated in $22 \%$ consecutive female patients with definite or classical rheumatoid arthritis (RA). A slight increase in the prevalence of DR4 with age at RA onset was found. This appeared to be due to the low percentage of rheumatoid factor (RF) positivity in the youngest age groups; the DR4 prevalence in the RF positive patients was constant for all decades-that is, approximately $60 \%$. $\vec{A}$ previously reported declining trend of DR4 prevalence in women with RA in relation to age RA onset may be due to the disease heterogeneity of the patients included in that study.

The relation between HLA-DR4 and rheumatoid arthritis (RA) has been well established. ${ }^{1-3}$ In previous studies a significantly higher HLA-DR4 prevalence was found in women with RA than in male patients, ${ }^{4}$ as well as a stronger association of HLA-DR4 with early onset RA. ${ }^{45}$ In one study the strong association between HLA-DR4 and early onset RA was seen only in women. ${ }^{6}$ The question whether HLA-DR4 is particularly associated with early onset disease in women is intriguing when one realises that the female to male incidence ratio in RA declines with age after 60 . Men of all ages above 15 are equally susceptible to the disease, whereas in women a marked increase in the prevalence of the disease occurs between the ages of 35 and 55 , together with a decrease at 60 and over. ${ }^{7}$

A particularly strong association between HLADR4 and early onset disease in women may be relevant to a consideration of the aetiology of $\mathrm{RA}$ in relation to gender and hormonal influences. The interpretation of results from HLA-RA association studies is difficult, however, owing to the disease heterogeneity of RA. It is well known that the HLA-DR4 antigen is preferentially associated with the more serious manifestations of the disease. ${ }^{8-11} \mathrm{~A}$ possible relation between DR4 and RA onset in women thus has to be established in a homogeneous

Accepted for publication 26 September 1988.

Correspondence to Dr J M W Hazes, Department of Rheumatology, Building 1, C2-Q, University Hospital, PO Box 9600, 2300 RC Leiden, The Netherlands. group of patients with RA. We therefore studied the relation between HLA-DR4 and age at disease onset in a well defined group of women with definite or classical RA.

\section{Patients and methods}

Two hundred and twenty six unrelated female Caucasoid patients with RA fulfilling the Americar? Rheumatism Association (ARA) criteria for defi政 nite or classical $R^{12}$ were studied. The younger $13 \vec{h}$ women, with age at disease onset between 16 and 59 years, were patients with symptoms of recent date who made their first visit to the rheumatology outpatient clinic in Leiden in the period 1982-6 They were initially enrolled in a case-control study on the association between RA and oraty contraceptives. ${ }^{13}$ The remaining group of 95 older patients with RA, with age at disease onset between 50 and 85 years, were consecutive patients at th $E^{5}$ outpatient rheumatology clinic during a three mont period in autumn 1986. For all women the age disease onset was defined as the age at onset of symptoms.

A group of 305 women with soft tissue rheumat ism or osteoarthritis, already tissue typed during the case-control study on the association between RA and oral contraceptives, ${ }^{13}$ served as controls. OA these women, both the HLA-DR4 status and age aT symptom onset were known. Because the maximung age of these controls was 50 years the HLA-DR龺 
Table 1 Distribution of patients with rheumatoid arthritis $(R A)$ over the decades and the percentages of rheumatoid factor $(R F)$ positivity and DR4 positivity in each group

\begin{tabular}{lllcr}
\hline $\begin{array}{l}\text { Decades } \\
\text { (years) }\end{array}$ & $\begin{array}{l}\text { Number of patients } \\
\text { with } R A\end{array}$ & $\begin{array}{l}\text { Number of } R F \\
\text { positive patients } \\
(\%)\end{array}$ & $\begin{array}{l}\text { Number with } \\
\text { DR4 positivity } \\
\text { in all patients } \\
(\%)\end{array}$ & $\begin{array}{l}\text { Number with } \\
\text { DR4 positivity } \\
\text { in } R F \text { positive patients } \\
(\%)\end{array}$ \\
\hline $16-25$ & & $10(48)$ & $6(29)$ & $6(60)$ \\
$26-35$ & 21 & $25(61)$ & $18(44)$ & $14(56)$ \\
$36-45$ & 41 & $40(74)$ & $32(59)$ & $29(73)$ \\
$46-55$ & 54 & $46(84)$ & $29(53)$ & $25(54)$ \\
$56-65$ & 55 & $19(79)$ & $12(50)$ & $9(47)$ \\
$66-75$ & 24 & $16(67)$ & $13(54)$ & $10(63)$ \\
$76-86$ & 24 & $2(29)$ & $2(29)$ & $1(50)$ \\
Total & 7 & $158(70)$ & $112(50)$ & $94(59)$
\end{tabular}

prevalence in the control group was validated against the HLA-DR4 antigen prevalence in a group of 1576 healthy, age matched, unrelated female Dutch Caucasoids.

LABORATORY TESTING AND ANALYSIS HLA-DR4 typing was carried out by the double fluorescence technique described by Van Rood et $a l .{ }^{14}$ The presence of rheumatoid factor (RF) was ascertained by the latex and Waaler-Rose tests. RF positivity was defined as latex determination $>12.50$ IU $(1 / 160)$ or Waaler-Rose value $>25$ IU $(1 / 16)$, or both.

The relation between DR4 and age at disease onset was described by the DR4 prevalence and the age at symptom onset. To allow for the small numbers at each individual age we used 10 year moving averages - that is, antigen prevalence of DR4 for age group 16-25 years, 17-26 years, 18-27 years, etc. The DR4 prevalences were calculated for the total RA group and separately for the RF positive and RF negative patients. $A \chi^{2}$ test was used for statistical analysis of the results.

\section{Results}

Table 1 shows the distribution of the patients with RA over the decades, and the fraction of RF positivity and DR4 positivity in these groups. Of all patients with $\mathrm{RA}, 70 \%$ were $\mathrm{RF}$ positive; the RF positive patients, however, were not evenly distributed over the decades. In the young and very old patients, especially, the percentage of RF positivity was low $-48 \%$ and $29 \%$ respectively. The prevalence of HLA-DR4 in the control group of women with soft tissue rheumatism or osteoarthritis was $29 \%$, similar to that in the healthy women. The prevalence of HLA-DR4 in all patients with RA was $50 \%$, which was significantly higher than that in the

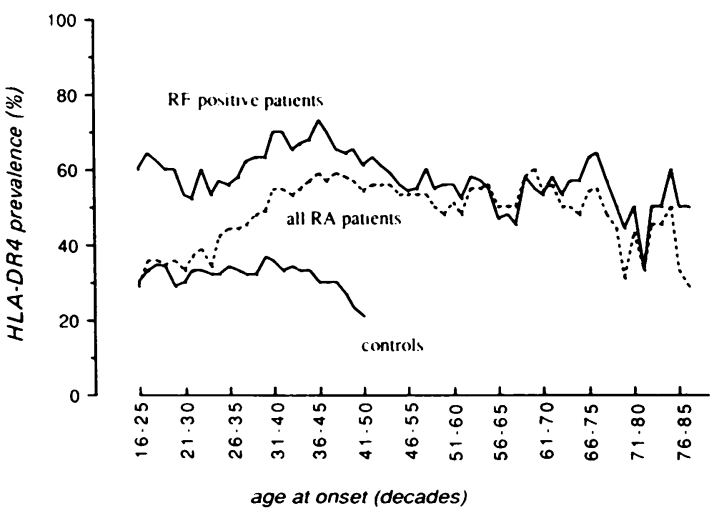

Fig. $1 H L A-D R 4$ prevalence in relation to age at disease onset. The age at disease onset is represented on the horizontal axis as 10 year moving averages, each point representing a 10 year interval as follows: 16-25, 17-26, 18-27, etc. $R A=$ rheumatoid arthritis; $R F=$ rheumatoid factor.

controls $(p<0 \cdot 001)$. The HLA-DR4 prevalence in the RF positive patients was $59 \%$, which was significantly higher than that in the RF negative patients with RA $(27 \%$; $p<0.0001)$.

Figure 1 presents graphically the relation between the prevalence of HLA-DR4 and age at disease onset. On the horizontal axis the age at disease onset is represented as 10 year moving averages as described in 'Patients and methods'. The prevalence of DR4, represented on the vertical axis, showed a slight increase in the period of RA onset from 16 to 40 years. This trend disappeared when the DR4 prevalences were calculated for the more homogeneous group of RF positive patients. The control group showed no relation between the prevalence of DR4 and the age at disease onset and 
fluctuated around the mean DR4 prevalence of the healthy female blood donors.

\section{Discussion}

In the present study of female patients with RA we could not confirm the previously reported declining trend in HLA-DR4 prevalence with the age at disease onset. ${ }^{6}$ There was even a slight increase in HLA-DR4 prevalence with age. This increase, however, could be attributed to the low percentage of $R F$ positivity in the youngest age groups as the HLA-DR4 prevalence in the RF positive patients was constant for all decades. A stronger association with DR4 in RF positive patients has also been reported in earlier studies. ${ }^{4}$ The discrepancy between the present study and earlier studies regarding DR4 and disease onset may well be due to variation in case definition and patient selection. For example, Jaraquemada et al used pooled patient data originating from eight separate studies with all different case selection criteria. ${ }^{6}$ In the present study we used a homogeneous group of consecutive patients with RA attending one outpatient clinic and selected by one investigator (JMWH) with the only selection criterion that of definite or classical RA, which enhances the reliability of our findings. As regards the variation of DR4 prevalence in the different subgroups of RA it is also possible that previous studies have overinterpreted the importance of the statistical significance of their findings.

It has been well established that the DR4 prevalence in RA varies considerably-namely, between $28 \%$ in patients with RA ascertained through a population survey ${ }^{15}$ and $92 \%$ in patients with RA with severe extra-articular disease. ${ }^{8-11}$ These differences may be explained by assuming that HLA-DR4 is either a marker for a susceptibility gene conferring susceptibility only to a severe type of RA with extra-articular manifestations, ${ }^{16}$ or a marker for a disease modifying gene. ${ }^{15}$ In both cases the HLADR4 prevalence should be similar for all age groups of disease onset in men and women unless the different subgroups in RA-for example, RF positive $R A$, vasculitis, have an age related disease onset. In that case one would expect to find a cluster of DR4 positivity at that specific age group. Some support for this hypothesis is found in publications reporting a lower prevalence of RF positivity and DR4 positivity in older age onset RA than in those with younger age onset RA. ${ }^{17} 18$

In conclusion, no trend was seen in HLA-DR4 prevalence with age at disease onset in RF positive women with RA. Only studies with strict selection criteria for the study subjects will give us more $\frac{}{\omega}$. insight into the association between RA and DR4.

The authors would like to thank Mrs G M Th Schreuder and collaborators for the HLA typing, Dr J D'Amaro for his help in providing the data of the blood donors, and Ms J Ravensbergen for secretarial assistance. This work was supported by the Dutch $\frac{\overline{\mathcal{S}}}{\bar{T}}$ Prevention Fund.

\section{References}

1 Stastny P. Association of the B-cell allo-antigen DRw4 with $\overrightarrow{0}$ rheumatoid arthritis. N Engl J Med 1978; 298: 869-72.

2 Panayi C S, Wooley P, Batchelor J R. Genetic basis of $\vec{\omega}$ rheumatoid disease: HLA antigens, disease manifestations, and $\overparen{ }$ toxic reactions to drugs. $\mathrm{Br}$ Med $J$ 1978; ii: 1326-8.

3 Karr R W, Rodey G E, Lee T, Schwartz B D. Association of HLA-DRw4 with rheumatoid arthritis in black and white $\underset{\infty}{\oplus}$ patients. Arthritis Rheum 1980; 23: 1241-5.

4 Gran J T, Husby G, Thorsby E. The association between: rheumatoid arthritis and the HLA antigen DR4. Ann Rheum Dis 1983; 42: 292-6.

5 Bardin T, Legrand L, Naveau B, et al. HLA antigens and seronegative rheumatoid arthritis. Ann Rheum Dis 1985; 44:-

6 Jaraquemada D, Ollier W, Awad J, et al. HLA and rheumatoid arthritis: a combined analysis of $\mathbf{4 4 0}$ British patients. Ann Rheum Dis 1986; 45: 627-36.

7 Short C L, Bauer W, Reynolds W E. Rheumatoid arthritis. Cambridge, Massachusetts: Harvard University Press, 1957.

8 Young A, Jaraquemada D, Awad J, et al. Association of HLA-DR4/DW4 and DR2/DW2 with radiologic changes in as prospective study of patients with rheumatoid arthritis. Arthritis Rheum 1984; 27: 20-5.

9 Walker D J, Griffiths M, Dewar P, et al. Association of MHC응 antigens with susceptibility to and severity of rheumatoid arthritis in multicase families. Ann Rheum Dis 1985; 44: 519-25.

10 Ollier W, Venables P J W, Mumford P A, et al. HLA antigen? associations with extra-articular rheumatoid arthritis. Tissue Antigens 1984; 24: 279-91.

11 Westedt M L , Breedveld F C, Schreuder G M Th, D'Amaro J. נִ Cats A, De Vries R R P. Immunogenetic heterogeneity ofō rheumatoid arthritis. Ann Rheum Dis 1986; 45: 534-8.

12 Ropes M W, Bennett G A, Cobb S, Jacox R, Jessar R A revision of diagnostic criteria for rheumatoid arthritis. Bulto Rheum Dis 1958; 9: 175-6.

13 Hazes M, Dijkmans B A C, Vandenbroucke J P, de Vries R R P, Cats A. The preventive effect of oral contraception ono the incidence of rheumatoid arthritis. Clin Exp Rheumatol 1987; 5 (suppl 2): 27.

14 Van Rood J J, van Leeuwen A, Ploem J S. Simultaneous detection of two cell populations by two-colour fluorescencen and application to the recognition of B-cell determinants. Nature 1976; 262: 795-7.

15 De Jongh B M, Van Romunde L K J, Valkenburg H A, de Lange G G, Van Rood J J. Epidemiological study of HLA and GM in rheumatoid arthritis and related symptoms in an oper Dutch population. Ann Rheum Dis 1984; 43: 613-9.

16 De Vries R R P, Nijenhuis L E, Khan M A, Mehra N K Paradoxical inheritance of HLA-linked susceptibility to rheumatoid arthritis. Tissue Antigens 1985; 26: 286-93.

17 Inoue K, Shichikawa K, Nishioka J, Hirota S. Older age onset⿱ rheumatoid arthritis with or without osteoarthritis. Ann Rheump Dis 1987; 46: 908-11.

18 Terkeltaub R, Decary F, Esdaile J. An immunogenetic study of older age onset rheumatoid arthritis. J Rheumatol 1984; 112 147-52. 